\title{
Factors that effect the success of embryo transfer in polo ponies
}

L Ticehurst, J Wiseman, H V Masey, O'Neill

University Of Nottingham, Leicestershire, United Kingdom

Email: helen.maseyoneill@nottingham.ac.uk

Introduction Embryo transfer is becoming increasingly important as a modern reproductive technology in the equine industry. Benefits include the production of multiple offspring from one mare (donor) in the same year; the ability to allow athletic mares to continue competing without time spent breeding; the maintenance of top bloodlines (Pashen et al, 1993); avoidance of infertility; reduction in the risk of disease spread and, due to the above reasons, huge financial advantages (Noakes et al, 2001). This study aimed to assess factors suggested to be important in the success rate of this procedure.

Materials and methods The embryo transfer (ET) method used was modified from that described by Douglas (1982), Paschen (1985) and Sertich (1989) whereby an embryo from a genetically superior mare and stallion is transferred to a less valuable donor mare that will carry it to term. All procedures were carried out in situ inclusive of treatments used to aid natural oestrous cyclicity and prepare some mares' uterine environment as well as semen extraction and the artificial insemination prior to ET. The donor mares all carried a high proportion of Thoroughbred (TB) blood and were polo ponies $(n=135)$, aged 2.5 to 28 years, weighing $350-500 \mathrm{~kg}$. The stallions $(n=17)$ used were mostly TB, and all were registered with the Argentine Association of Breeders of Horses for Polo. They ranged in age from 3 to 28 years old and all had proven fertility. The recipient mares $(n=504)$ were Criollo, semi wild and handled minimally. The mares were selected on the basis of specific criteria related to age (3-9 years), size, body condition, conformation, type, temperament, and normality of the reproductive tract (as described in Paschen et al, 1993). If recipient mares did not retain a pregnancy and no abnormalities were detected they were reused. Synchronisation of oestrus cycles between donor and recipient mares ranged from -1 , when the recipient ovulates the day before the donor, to +4 days when the recipient ovulates 4 days after the donor. This was primarily achieved through the natural cyclicity of the mares enabled by the ratio of donor to recipient mares. The main measurement of interest was pregnancy diagnosis; this was achieved by rectal palpation and ultrasonography. Success was defined as a positive pregnancy diagnosis 60 days post ovulation. Statistical analysis was carried out using SAS (SAS Institute Inc). Initially, individual variables were analysed using linear regression. In the final statistical model, data was entered into a logistic regression output incorporating all significant variables as a combination.

Results The results of the linear regressions are shown in table 1. The following were also significant, but were not entered into the logistic regression due to low numbers of observations. The stallion has a significant $(\mathrm{p}<0.001, \mathrm{df}=47)$ effect on embryonic development and growth. There was a significant interaction between the location within the ovaries (bilateral/unilateral) and the relative timing of each ovulation (synchronised/unsynchronised) $(\mathrm{p}<0.001, \mathrm{df}=3$,). The ET clinician was an important factor with variation in success rate of between $27 \%$ and $82 \%$.

Table 1 The effects of individual variables on the success of ET (linear regression)

\begin{tabular}{lll}
\hline \hline Variable & Significance & Relationship \\
\hline Age of mare & $\mathrm{P}<0.001$ & Negative \\
Ovulation to flush interval & $\mathrm{p}<0.001$ & Negative \\
Embryo number & $\mathrm{p}<0.001$ & Positive \\
Time embryo stored & $\mathrm{NS}$ & \\
Presence of uterine debris & $\mathrm{P}=0.011$ & Negative \\
Flush date & $\mathrm{P}=0.008$ & Negative \\
Hour of day & $\mathrm{P}=0.040$ & Positive \\
AI to flush interval & $\mathrm{P}=0.029$ & Negative \\
Environmental temperature & $\mathrm{NS}$ & \\
Flushes per mare & $\mathrm{P}=0.016$ & Negative \\
Artificial Insemination & $\mathrm{NS}$ & \\
Rainfall & $\mathrm{NS}$ & \\
\hline \hline
\end{tabular}

After the logistic regression, 3 variables remained significant $P<0.001$ (highlighted in Table 1). The logistic regression suggests the following equation to predict success:

$1.5001+(\mathrm{x} *-0.0538)+(\mathrm{y} *-0.4038)+(\mathrm{z} * 2.6973)$

Where $\mathrm{x}=$ age in years, $\mathrm{y}=$ ovulation to flush interval in days and $\mathrm{z}=$ number of embryos. A probability score is thus generated.

\section{Conclusion}

It was established that there should be a higher success rate for younger mares, a shorter ovulation to flush interval and greater embryo number produced (ovulation). Weather (temperature and rainfall) were not significant variables which was unexpected due to the nature of the recipient management and the nutritional content of their grazing. An experienced clinician and proven stallion is required to optimise this procedure. If the success of ET can be improved there are huge economical implications within all performance equine industries as it enables use of the best genetics in competitive careers as well as for breeding.

\section{Acknowledgements}

Diego Rodriguez Piola (MV), the director and head veterinarian of Ellerstina's ET centre "La Grappa": (Casbas, Trenque Lauquen, Buenos Aires, Argentina); Angela Beresford (PhD) and Amber Clutton-Brock (MRCVS).

\section{References}

Douglas, R.H. 1982. Journal of Reproduction and Fertility 32, 405-408

Noakes D.E. et al. 2001. Arthur's Veterinary Reproduction and Obstetrics. $8^{\text {th }}$ Edition, Blackwells

Paschen, R.L. 1985. Theriogenology 142-146

Paschen, R.L et al. 1993. Equine Veterinary Journal 15, 119 - 121

Sertich, P.L. 1989. Journal of the American Veterinary Medical Association 195, 940-944 